\title{
Image Processing and Analysis
}

\author{
I. A. Ansari ${ }^{1}$, R. Y. Borse ${ }^{2}$ \\ ${ }^{1}$ Dept. of Computer Science, M.S.G. College, Malegaon, Dist-Nasik, India \\ ${ }^{2}$ Dept of Electronic Science, M.S.G. College, Malegaon, Dist-Nasik, India
}

\begin{abstract}
This paper describes the basic technological aspects of Digital Image Processing. Basically, all image-processing operations can be grouped into three categories: Image Rectification and Restoration, Enhancement and Information Extraction. The former deals with initial processing of raw image data to correct for geometric distortion to calibrate the data radiometrically and to eliminate noise present in the data. The enhancement procedures are applied to image data in order to effectively display the data for subsequent visual interpretation. It involves techniques for increasing the visual distinction between features in a scene. The objective of the information extraction operations is to replace visual analysis of the image data with quantitative techniques for automating the identification of features in a scene. This involves the analysis of multispectral image data and the application of statistically based decision rules for determining the land cover identity of each pixel in an image. The intent of classification process is to categorize all pixels in a digital image into one of several land cover classes or themes. This classified data may be used to produce thematic maps of the land cover present in an image.
\end{abstract}

Keywords - digital Image, radio metrically, noise, multi spectral, pixels.

\section{INTRODUCTION}

The field of digital image processing refers to processing digital images by means of a digital computer. A digital image is composed of a finite number of elements each of which has a particular location and value. These elements are referred to as pixel. One useful paradigm in digital image processing is to consider three types of computerized processes [1] (Figure 1). First Importing the image with optical scanner or by digital photography, second Analyzing and manipulating the image which includes data compression and image enhancement and spotting patterns that are not to human eyes like satellite photographs and third output is the last stage in which result can be altered image or report that is based on image analysis.

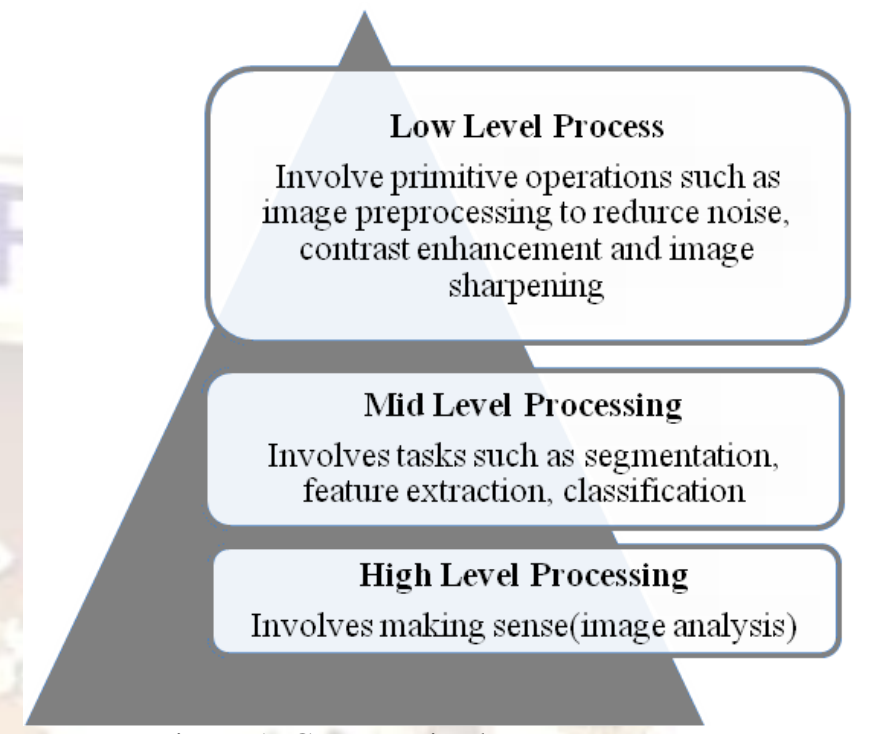

Figure 1: Computerized Processes

II. IMAGE PROCESSING

Image processing is a method to convert an image into digital form and perform some operations on it, in order to get an enhanced image or to extract some useful information from it. It is a type of signal dispensation in which input is image, like video frame or photograph and output may be image or characteristics associated with that image. Usually Image Processing system includes treating images as two dimensional signals while applying already set signal processing methods to them. Assume that an image $\mathrm{f}(\mathrm{x}, \mathrm{y})$ is sampled so that the resulting digital image has $\mathrm{M}$ rows and $\mathrm{N}$ columns. The values of the coordinates $(\mathrm{x}, \mathrm{y})$ now become discrete quantities. For notational clarity and convenience, we shall use integer values for these discrete coordinates. Thus, the values of the coordinates at the origin are $(x, y)=$ $(0,0)$. The next coordinate values along the first row of the image are represented as $(x, y)=(0,1)$. It is important to keep in mind that the notation $(0,1)$ is used to signify the second sample along the first row. It does not mean that these are the actual values of physical coordinates when the image was sampled. Figure 2 shows the coordinate convention used. 


\section{A. Ansari, R. Y. Borse / International Journal of Engineering Research and Applications \\ (IJERA) ISSN: 2248-9622 www.ijera.com Vol. 3, Issue 4, Jul-Aug 2013, pp.1655-1658}

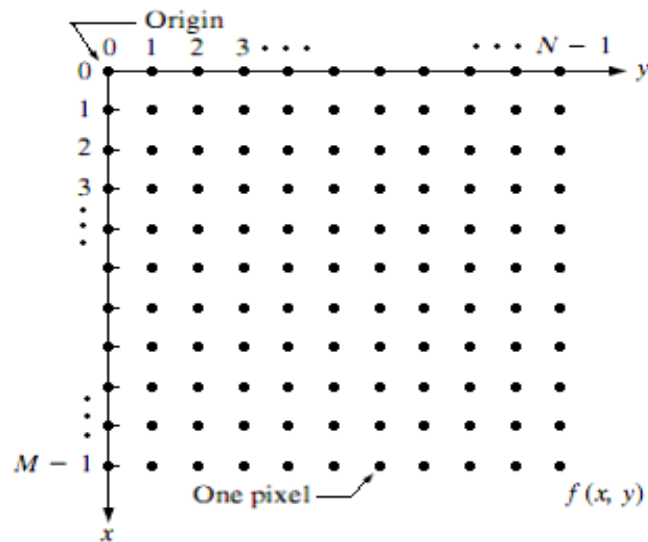

Figure 2: Coordinate convention used to represent digital images

The notation introduced in the preceding paragraph allows us to write the complete $\mathrm{M} * \mathrm{~N}$ digital image in the following compact matrix form:

$$
f(x, y)=\left[\begin{array}{cccc}
f(0,0) & f(0,1) & \cdots & f(0, N-1) \\
f(1,0) & f(1,1) & \cdots & f(1, N-1) \\
\vdots & \vdots & & \vdots \\
f(M-1,0) & f(M-1,1) & \cdots & f(M-1, N-1)
\end{array}\right]
$$

The right side of this equation is by definition a digital image.

\section{A. Methods used for Image Processing}

The two types of methods used for Image Processing are Analog and Digital Image Processing. Analog or visual techniques of image processing can be used for the hard copies like printouts and photographs. Image analysts use various fundamentals of interpretation while using these visual techniques. The image processing is not just confined to area that has to be studied but on knowledge of analyst. Association is another important tool in image processing through visual techniques. So analysts apply a combination of personal knowledge and collateral data to image processing.

Digital Processing techniques help in manipulation of the digital images by using computers. Following Diagram show fundamental steps but as they are fundamental, all these steps may have sub-steps.

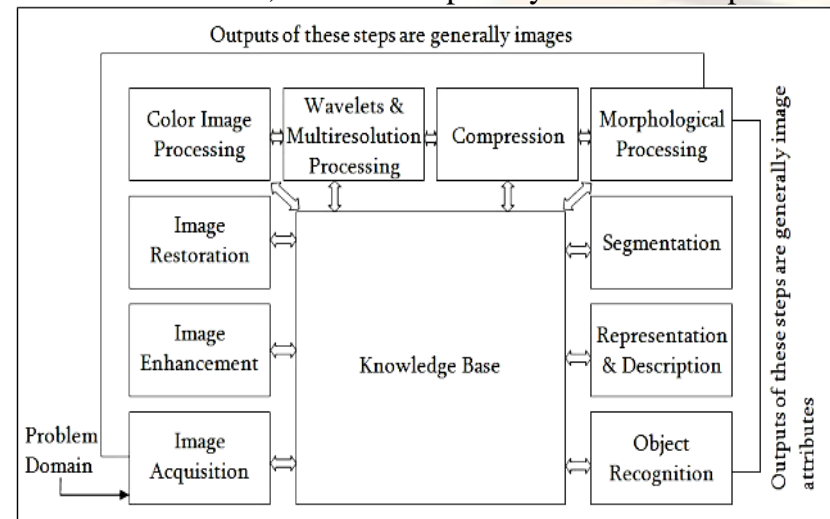

Figure 3: Fundamental steps digital processing
Image Acquisition: This is the first step or process of the fundamental steps of digital image processing. Image acquisition could be as simple as being given an image that is already in digital form. Generally, the image acquisition stage involves preprocessing, such as scaling etc.

Image Enhancement: Image enhancement is among the simplest and most appealing areas of digital image processing. Basically, the idea behind enhancement techniques is to bring out detail that is obscured, or simply to highlight certain features of interest in an image such as changing brightness and contrast etc.

Image Restoration: Image restoration is an area that also deals with improving the appearance of an image. However, unlike enhancement, which is subjective, image restoration is objective, in the sense that restoration techniques tend to be based on mathematical or probabilistic models of image degradation.

Color Image Processing: Color image processing is an area that has been gaining its importance because of the significant increase in the use of digital images over the Internet. This may include color modeling and processing in a digital domain etc.

Wavelets and Multiresolution Processing: Wavelets are the foundation for representing images in various degrees of resolution. Images are subdivision successively into smaller regions for data compression and for pyramidal representation.

Compression: Compression deals with techniques for reducing the storage required to save an image or the bandwidth to transmit it. Particularly in the uses of internet it is very much necessary to compress data.

Morphological Processing: Morphological processing deals with tools for extracting image components that are useful in the representation and description of shape.

Segmentation: Segmentation procedures partition an image into its constituent parts or objects. In general, autonomous segmentation is one of the most difficult tasks in digital image processing. A rugged segmentation procedure brings the process a long way toward successful solution of imaging problems that require objects to be identified individually.

Representation and Description: Representation and description almost always follow the output of a segmentation stage, which usually is raw pixel data, constituting either the boundary of a region or all the points in the region itself. Choosing a representation is only part of the solution for transforming raw data into a form suitable for subsequent computer processing. Description deals with extracting attributes that result in some quantitative information of interest or are basic for differentiating one class of objects from another.

Object recognition: Recognition is the process that assigns a label, such as, "vehicle" to an object based on its descriptors. 


\section{A. Ansari, R. Y. Borse / International Journal of Engineering Research and Applications (IJERA) ISSN: 2248-9622 www.ijera.com Vol. 3, Issue 4, Jul-Aug 2013, pp.1655-1658}

Knowledge Base: Knowledge may be as simple as detailing regions of an image where the information of interest is known to be located, thus limiting the search that has to be conducted in seeking that information. The knowledge base also can be quite complex, such as an interrelated list of all major possible defects in a materials inspection problem or an image database containing high-resolution satellite images of a region in connection with changedetection applications.

\section{B. Purpose of Image processing}

The purpose of image processing is divided into 5 groups. They are:

Visualization: Observe the objects that are not visible.

Image sharpening and restoration: To create a better image.

Image retrieval: Seek for the image of interest.

Measurement of pattern: Measures various objects in an image.

Image Recognition: Distinguish the objects in an image.

TABLE I

HISTORY [3]

\begin{tabular}{|c|c|}
\hline Year & Application \\
\hline $\begin{array}{l}\text { Early } \\
1920\end{array}$ & $\begin{array}{l}\text { An image was transferred by submarine } \\
\text { cable between London and New York. } \\
\text { Pictures were coded for cable transfer and } \\
\text { reconstructed at the receiving end on a } \\
\text { telegraph printer }\end{array}$ \\
\hline $\begin{array}{l}\text { Mid } \\
\text { to late } \\
1920\end{array}$ & $\begin{array}{l}\text { Improvements to the Bartlane system } \\
\text { resulted in higher quality images } \\
\text { - New reproduction processes based on } \\
\text { photographic techniques } \\
\text { - Increased number of tones in reproduced } \\
\text { images } 15 \text { tone digital image }\end{array}$ \\
\hline 1960 & $\begin{array}{l}\text { Improvements in computing technology } \\
\text { and the on set of the space race led to a } \\
\text { surge of work in digital image processing } \\
\text { Many of the techniques of digital image } \\
\text { processing, or digital picture processing } \\
\text { were developed in the 1960s at the Jet } \\
\text { Propulsion Laboratory, Massachusetts } \\
\text { Institute of Technology, Bell Laboratories, } \\
\text { University of Maryland, and a few other } \\
\text { research facilities, with application to } \\
\text { satellite imagery, wire-photo standards } \\
\text { conversion, medical imaging, videophone, } \\
\text { character recognition, and photograph } \\
\text { enhancement.[4] }\end{array}$ \\
\hline 1964 & $\begin{array}{l}\text { Computers used to improve the quality of } \\
\text { images of the moon taken by Ranger } 7 \\
\text { probe ,techniques were used in other space } \\
\text { missions including the Apollo landings A } \\
\text { picture of the moon taken } 17 \text { minutes } \\
\text { before landing in } 1964\end{array}$ \\
\hline 1970 & $\begin{array}{l}\text { Digital image processing begins to be used } \\
\text { in medical applications and in real time, }\end{array}$ \\
\hline
\end{tabular}

\begin{tabular}{|l|l|}
\hline & $\begin{array}{l}\text { for some dedicated problems such as } \\
\text { television standards conversion.[4] } \\
\text { computerized axial tomography (CAT } \\
\text { scanning), digitization of analog images } \\
\text { allowed the enhancement and restoration of } \\
\text { archaeological artefacts and began to be } \\
\text { used in fields as diverse as nuclear } \\
\text { medicine, astronomy, law enforcement, } \\
\text { defence and industry.[5] }\end{array}$ \\
\hline 1979 & $\begin{array}{l}\text { Sir Godfrey N. Hounsfield \& Prof. Allan } \\
\text { M. Cormack share the Nobel Prize in } \\
\text { medicine for the invention of tomography, } \\
\text { the technology behind Computerized Axial } \\
\text { Tomography (CAT) scans Typical head } \\
\text { slice CAT image }\end{array}$ \\
\hline 1980 & $\begin{array}{l}\text { The use of digital image processing } \\
\text { techniques has exploded and they are now } \\
\text { used for all kinds of tasks in all } \\
\text { Today } \\
\text { kinds of areas } \\
- \text { Image enhancement/restoration } \\
- \text { Artistic effects } \\
- \text { Medical visualization } \\
- \text { Industrial inspection } \\
- \text { Law enforcement } \\
- \text { Human computer interfaces }\end{array}$ \\
\hline
\end{tabular}

\section{APPLICATIONS}

The following is an imaginative list of possible uses:

Air traffic control could be automated with the location, altitude, direction and speed of each radar blip as input to the network. The output would be the air traffic controllers instruction to each blip.

Animal behavior, predator/prey relationships, and population cycles may be suitable for analysis by neural networks.

Anomaly detection is a way to uncover certain data records which do not fit the pattern of their peers.

Appraisal and valuation of property, buildings, automobiles, machinery, etc. should be an easy task for a neural network.

Betting on horse races, stock markets, sporting events, etc. could be based on neural network predictions.

Criminal sentencing could be predicted using a large sample of crime details as input and the resulting sentences as output.

Complex physical and chemical processes that may involve the interaction of numerous (possibly unknown) mathematical formulas can be modeled heuristically using a neural network.

Data mining, cleaning \& validation can be achieved by determining which records suspiciously diverge from the pattern of their peers.

Direct mail advertisers could use neural network analysis of their database to decide which customers should be targeted, and avoid wasting money on unlikely targets. 


\section{A. Ansari, R. Y. Borse / International Journal of Engineering Research and Applications (IJERA) ISSN: 2248-9622 www.ijera.com Vol. 3, Issue 4, Jul-Aug 2013, pp.1655-1658}

Echo patterns from sonar, radar, seismic and magnetic instruments can be used to predict their targets.

Econometric modeling based on neural networks should be more realistic than older models based on classical statistics.

Employee hiring could be optimized if the neural network were able to predict which job applicant will achieve the best job performance.

Expert consultants could package their intuitive expertise into a neural network, to automate their services.

Factories could predict their demand for electricity. Then load shedding could be done to reduce the electric bill, and reduce impact on the power company.

Fraud detection regarding credit cards, insurance or taxes could be automated using a neural network analysis of past incidents.

Handwriting and typewriting can be recognized by imposing a grid over the writing, then each square of the grid becomes an input to the neural network. This is called "Optical Character Recognition"

Lake water levels could be predicted based on precipitation patterns and River/Dam flows.

Machinery control could be automated by capturing the actions of experienced machine operators into a neural network.

Medical diagnosis is an ideal application for neural networks.

Medical research relies heavily on classical statistics to analyze research data. Perhaps a neural network should be included in the researcher's toolkit.

Music composition has been tried using neural networks. The network is trained to recognize patterns in the pitch and tempo of certain music, then the network writes its own music.

Photos \& fingerprints could be recognized by imposing a fine grid over the photo. Each square of the grid becomes an input to the network.

Recipes and chemical formulations could be optimized based on the predicted outcome of a formula change.

Retail inventories could be optimized by predicting demand based on past patterns.

River water levels could be predicted based on upstream reports, and the time and location of each report.

Scheduling of buses, airplanes, and elevators" could be optimized by predicting demand.

Staff scheduling requirements for restaurants, retail stores, police stations, banks, etc. could be predicted based on day of week, pay-days, holidays, weather, season, etc.

Strategies for games, business and war can be captured by analyzing the expert player's response to given stimuli. For example, a football coach must decide whether to kick, pass, or run on the last down.
The inputs for this decision include score, time, field location, yards to first down, etc.

Traffic flows could be predicted, so that signal timing could be optimized. The network could recognize "a weekday morning rush hour during a school holiday" or "a typical winter Sunday morning."

Voice recognition can be obtained by analyzing the audio oscilloscope pattern, much like a stock market graph.

Weather prediction may be possible. Inputs would include weather reports from surrounding areas. Output(s) would be the future weather in our area. Effects like ocean currents and jet stream could be included. [7]

\section{CONCLUSION}

Digital Image Processing is among rapidly growing technologies today, with its applications in various aspects of a business. Image Processing forms core research area within engineering and computer science disciplines too.

\section{REFERENCES}

[1] Gonzalez, Rafael, C; Woods, Richard E (2008), Digital Image Processing, 3rd Edition, PearsonPrentice Hall. pp. 577, ISBN 013168728.

[2] www.doc.ic.ac.uk/ nd/surprise 96/journal/ vol4/cs11/report.html

[3] http://www.cs.uoi.gr/ cnikou/Courses/ Digital Image Processing/ Chapter-01 _Introduction_2spp.pdf

[4] Geva, A. (1998) ScaleNet-Multiscale Neural-Network Architecture for Time Series Prediction. IEEE Transactions on Neural Networks, 9(5), 1471- 1482.

[5] http://books.google.com/books?id=8uG OnjRGEzoC and printsec $=$ frontcover $\&$ $\mathrm{dq}=\% 22$ digital+image + processing $\% 22+$ gon zalez\# $\mathrm{v}=$ onepage and $\mathrm{q}=$ and $\mathrm{f}=$ false

[6] http://www.engineersgarage.com/

[7] http://www.cormactech.com/neunet/whatis .html 